\title{
Triethylammonium hydrogen sulfate ionic liquid as a low-cost solvent: A short review of synthesis, analysis and applications
}

\author{
S. M. Shahrul Nizan Shikh Zahari ${ }^{1, *}$, Hazeeq Azman ${ }^{2}$ and Latifah Karim ${ }^{1}$ \\ ${ }^{1}$ Faculty of Science and Technology, Universiti Sains Islam Malaysia, Bandar Baru Nilai, \\ 71800 Nilai, Negeri Sembilan, Malaysia. \\ ${ }^{2}$ Department of Science and Biotechnology, Faculty of Engineering and Life Sciences, \\ Universiti Selangor, 45600 Bestari Jaya, Selangor, Malaysia.
}

\begin{abstract}
This review does not attempt to be comprehensive, but it briefly introduces triethylammonium hydrogen sulfate ionic liquid ([ $\left.\left.\mathrm{N}_{2220}\right]\left[\mathrm{HSO}_{4}\right] \mathrm{IL}\right)$, which has been regarded as a low-cost solvent. It provides guidance regarding the synthesis procedures of the IL and several routine assessments for gaining insight into the properties of the IL. The review also selects examples of applications wherein the IL has been applied. It is hoped that the review will stimulate more research utilising the $\left[\mathrm{N}_{2220}\right]\left[\mathrm{HSO}_{4}\right] \mathrm{IL}$ across various disciplines of science and engineering.
\end{abstract}

\section{Introduction}

Solvents are important either for domestic or commercial uses due to their various functions. In chemical production, solvents serve as media for chemical reactions and reagents for purification/separation of chemicals [2]. However, the majority of solvents employed, such as dicloromethane $\left(\mathrm{CH}_{2} \mathrm{Cl}_{2}\right)$ and tricloromethane $\left(\mathrm{CH}_{3} \mathrm{Cl}\right)$, are volatile organic solvents (VOS), and they carry negative effects to human health and the environment. Ionic liquids (ILs), often regarded as so-called 'green solvents', have been proposed as alternatives to VOS. They are liquids at room temperature (or just above up to $100{ }^{\circ} \mathrm{C}$ ) and entirely composed of ions [3]. Unlike common organic solvents, ILs possess remarkable physical properties, including vanishing vapour pressure, large liquidous range, high thermal stability, good ionic conductivity, and favourable solvation behaviour [3]. This has resulted in ILs being widely employed in various areas of research at laboratory, such as biomass deconstruction [1,4,5], metal extraction [6,7], and catalysis [8]. Despite promising advantages, most ionic liquids are inherently expensive; a major obstacle for many commercial applications. As an example, at the time of writing, the intensively studied 1-butyl-3-methylimidazolium acetate ionic liquid $\left(\left[\mathrm{C}_{4} \mathrm{C}_{1} \mathrm{im}\right]\left[\mathrm{CH}_{3} \mathrm{COO}\right]\right)$ is sold at $\$ 881 \mathrm{~kg}^{-1}$ (CAS Number 284049-75-8, Sigma-Aldrich). One must note that prices for small

\footnotetext{
* Corresponding author: shahrul.zahari@usim.edu.my
} 
quantities should not be treated as the primary guide for commercial utility, but, it is estimated that ILs are 5-20 times more expensive than molecular solvents [9].

In order to ensure commercial utilisation of ILs a practical reality, the purchasing price of ILs needs to be reduced. A way to achieve this is by formulating ILs where their synthesis must be simple and straightforward (at manufacturing scale) consuming inexpensive reagents with minimising environmental impact. Triethylammonium hydrogen sulfate, $\left(\left[\mathrm{N}_{2220}\right]\left[\mathrm{HSO}_{4}\right]\right)$ is one of the ILs that meets the aforementioned criteria. Chen et al. conducted the first study on modelling and simulation of the production process of the $\left[\mathrm{N}_{2220}\right]\left[\mathrm{HSO}_{4}\right]$ IL using Aspen Plus V7.3 [9]. The simulation estimated the cost price of the IL would be $\$ 1.24 \mathrm{~kg}^{-1}[4,9]$.

\section{Synthesis of the [ $\left.\mathrm{N}_{2220}\right]\left[\mathrm{HSO}_{4}\right] \mathrm{IL}$}

The $\left[\mathrm{N}_{2220}\right]\left[\mathrm{HSO}_{4}\right]$ IL can be easily prepared via a simple acid-base neutralisation reaction involving inexpensive reagents: triethylamine $\left(\mathrm{N}_{222}\right)$, sulfuric acid $\left(\mathrm{H}_{2} \mathrm{SO}_{4}\right)$ and water $[1,4,9,10]$. Based on the Sigma-Aldrich's price check, the first and the second reagents cost not more than $\$ 100 \mathrm{~L}^{-1}$. More importantly, the synthesis guarantees $100 \%$ yield and produces the IL in double quantity, with only water as the by-product. A report by Shikh Zahari et al. can be referred for detailed synthesis procedures of the $\left[\mathrm{N}_{2220}\right]\left[\mathrm{HSO}_{4}\right] \mathrm{IL}$ (a summary is shown in Fig. 1) [1].

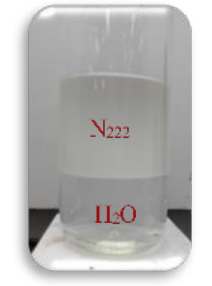

(a) An immiscible $\mathrm{N}_{222}-\mathrm{II}_{2} \mathrm{O}$ mixture

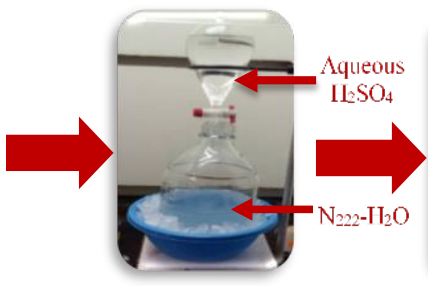

(b) Titration of $\mathrm{N}_{222}-\mathrm{II}_{2} \mathrm{O}$ with aqueous $\mathrm{H}_{2} \mathrm{SO} 4$ (c) A colourless solution of $\left[\mathrm{N}_{2220}\right]\left[\mathrm{HSO}_{4}\right]$ dissolved in $\mathrm{H}_{2} \mathrm{O}$

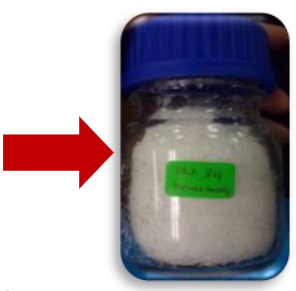

(d) Dried $\left.\mathrm{N}_{2220}\right]\left[\mathrm{HSO} \mathrm{IS}_{4}\right] \mathrm{II}$.

Fig. 1. Synthesis route of the $\left[\mathrm{N}_{2220}\right]\left[\mathrm{HSO}_{4}\right] \mathrm{IL}$ reported by Shikh Zahari et al.[1].

The synthesis has three subsequent steps. In Step 1, $\mathrm{N}_{222}$ is mixed with water, forming an immiscible mixture (Fig. 1 (a)). Step 2 involves dropwise addition of aqueous $\mathrm{H}_{2} \mathrm{SO}_{4}$ to the $\mathrm{N}_{222}-\mathrm{H}_{2} \mathrm{O}$ mixture at room temperature (Fig. 1 (b)), and the reaction is likely to follow mechanism in Fig. 2.

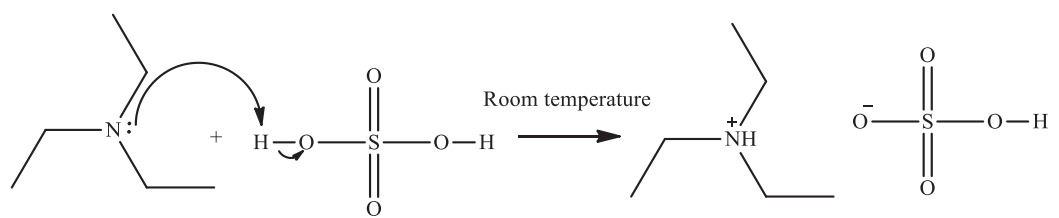

Fig. 2. Mechanism of the synthesis of the $\left[\mathrm{N}_{2220}\right]\left[\mathrm{HSO}_{4}\right]$ IL $[1,4]$.

Fig. 2 demonstrates that the reaction progresses via complete proton transfer. This is based on the fact that the $\mathrm{p} K_{a}$ difference between $\mathrm{N}_{222}\left(\mathrm{p} K_{a}=18\right)$ and $\mathrm{H}_{2} \mathrm{SO}_{4}\left(\mathrm{p} K_{a}=-3\right)$ is greater than 10, which is in good agreement with the prediction of Angell et al. [11]. Complete proton transfer (as shown mechanism in Fig. 2) leads to the formation of a salt, consisting of $\left[\mathrm{N}_{222}\right]^{+}$cation and $\left[\mathrm{HSO}_{4}\right]^{-}$anion, that is soluble in water (Fig. 1 (c)). This can also be an indicator of the reaction completion, as evidenced by the formation of a single phase and clear solution (Fig. 1 (c)). Step 3, removal of excess water from the IL, is 
optional depending on targeted applications. If the presence of water is undesired, the removal of excess water must be conducted to yield a dried IL (Fig. 1 (c)), otherwise, the drying step can be omitted.

\section{Analysis of the $\left[\mathrm{N}_{2220}\right]\left[\mathrm{HSO}_{4}\right]$ IL}

\subsection{Composition}

Nucleus magnetic resonance (NMR) analysis is a routine assessment conducted on newly synthesised ILs. It is to confirm molecular structures of ILs. A previous study compared the $\left[\mathrm{N}_{2220}\right]\left[\mathrm{HSO}_{4}\right]$ IL and fresh $\mathrm{N}_{222}$; the obtained spectra are shown in Fig. 3 [1].

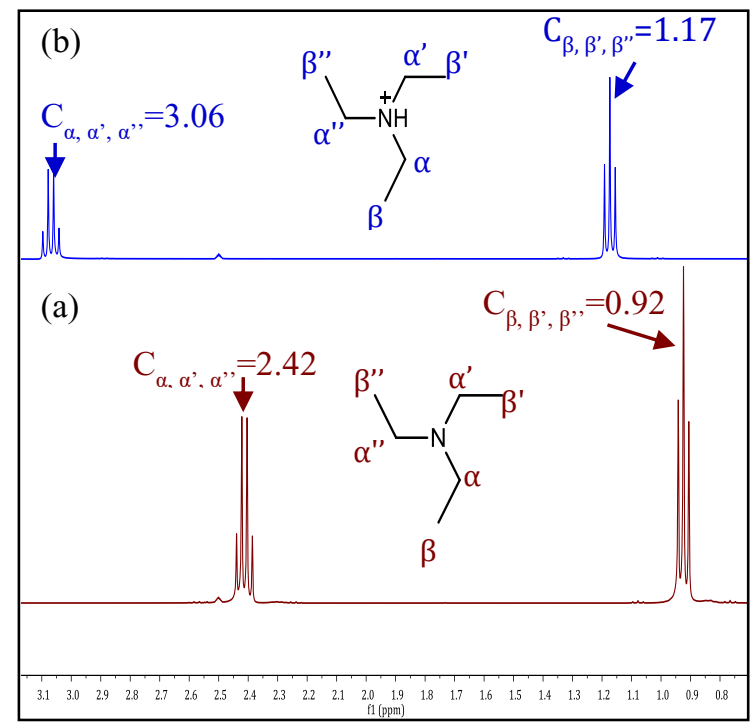

Fig. 3. ${ }^{1} \mathrm{H}-\mathrm{NMR}$ spectra of (a) fresh $\mathrm{N}_{222}$, and (b) the $\left[\mathrm{N}_{2220}\right]\left[\mathrm{HSO}_{4}\right]$ IL reported by Shikh Zahari et al. [1].

Compared to the fresh $\mathrm{N}_{222}$ (Fig. 3 (a)), all $\delta$ values in the IL's spectrum (Fig. 3 (b)) shifted downfield. This was deemed to be a strong indicative of the presence of a positive charge on the $\mathrm{N}$ in $\mathrm{N}_{222}\left(\mathrm{~N}^{+}\right)$owing to protonation by $\underline{\mathrm{HO}}$ in $\mathrm{H}_{2} \mathrm{SO}_{4}$. The presence of $\mathrm{N}^{+}$ affords an inductive effect that pulls electron density from the proton nuclei on $\mathrm{C} \alpha$ and $\mathrm{C} \beta$. As a result, the proton nuclei experiences greater effective magnetic field, as reflected by higher frequency absorbed (Fig. 3 (b)) [1]. The outcomes of this analysis further support the proposed mechanism in Fig. 2.

\subsection{Thermal Stability}

Thermogravimetric analysis (TGA) provides information on the decomposition pattern of ILs. Fig. 4 displays the decomposition profile of the $\left[\mathrm{N}_{2220}\right]\left[\mathrm{HSO}_{4}\right] \mathrm{IL}$ as reported by Shikh Zahari et al. [1]. It describes that the IL remains thermally stable but begins to decompose when heated above ca. $260{ }^{\circ} \mathrm{C}$. This characteristic is advantageous to many applications, such biomass deconstruction where most effective process utilising ILs occur at 150 $170^{\circ} \mathrm{C}$. 


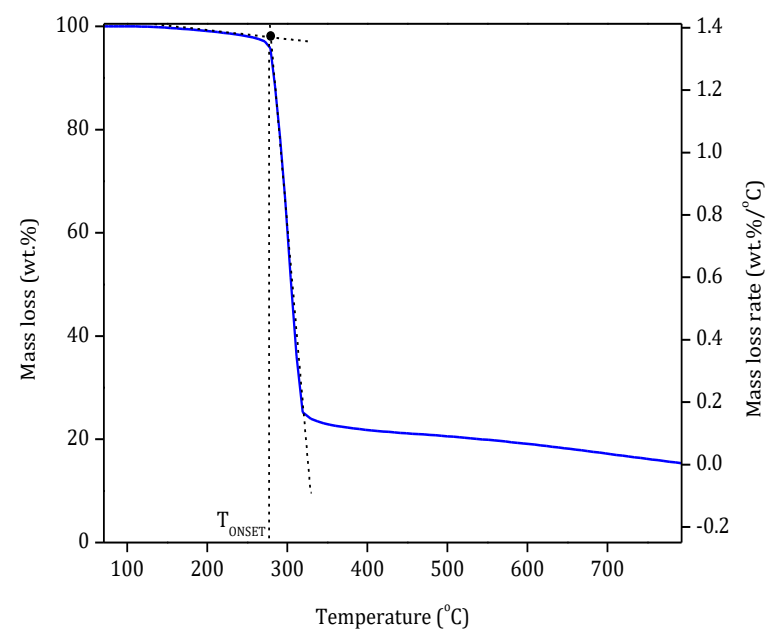

Fig. 4. TGA-Decomposition profile of the $\left[\mathrm{N}_{2220}\right]\left[\mathrm{HSO}_{4}\right]$ IL as a function of temperature $\left(10{ }^{\circ} \mathrm{Cmin}^{-1}\right.$ with $\mathrm{N}_{2}$ flow rate of $\left.10 \mathrm{mLmin}^{-1}\right)$ reported by Shikh Zahari et al. [1].

\subsection{Stoichiometry (Acid:Base Ratio)}

The proposed mechanism in Fig. 2 shows that the $\left[\mathrm{N}_{2220}\right]\left[\mathrm{HSO}_{4}\right]$ IL is formed by a stoichiometric reaction between $\mathrm{N}_{222}$ and $\mathrm{H}_{2} \mathrm{SO}_{4}$ (mole ratio of $\mathrm{N}_{222}: \mathrm{H}_{2} \mathrm{SO}_{4}$ is 1:1). However, common experimental errors often lead to non-stoichiometric reaction, yielding the IL with a slight excess of $\mathrm{N}_{222}$ or $\mathrm{H}_{2} \mathrm{SO}_{4}$. For some applications, this requires close monitoring as a small change in acid: base ratio may bring positive or negative outcomes on chemical processes.

A method developed by M. S.Y. Jennings can be referred to determine the mole ratio of $\mathrm{H}_{2} \mathrm{SO}_{4}: \mathrm{N}_{222}$ of the IL [12]. The procedure is as follows: (1) dissolve dried IL (Fig. 1 (d)) in deionised water (IL: $\mathrm{H}_{2} \mathrm{O}$ ratio of 80:20 wt:wt); (2) measure the density of the resultant IL- $\mathrm{H}_{2} \mathrm{O}$ solution; (3) insert the obtained density value, $y$, into Equation 1:

$$
y=0.0772 x+1.1135
$$

where $y$ is the density of the IL- $\mathrm{H}_{2} \mathrm{O}$ solution, and $x$ is the $\mathrm{H}_{2} \mathrm{SO}_{4}: \mathrm{N}_{222}$ ratio. The following conclusion can then be drawn from the measurement: if $x>1$, the IL contains an excess amount of unreacted $\mathrm{H}_{2} \mathrm{SO} 4$; if $x<1$, the IL contains an excess amount of untreated $\mathrm{N}_{222}$. This conclusion can be further confirmed by measuring the $\mathrm{pH}$ of the $\mathrm{IL}-\mathrm{H}_{2} \mathrm{O}$ solution, as performed by Weigand et al.[10]. In short, the greater the density, the higher the $\mathrm{H}_{2} \mathrm{SO}_{4}: \mathrm{N}_{222}$ ratio, but the lower the $\mathrm{pH}$ value.

\section{Applications of the [ $\left.\mathrm{N}_{2220}\right]\left[\mathrm{HSO}_{4}\right] \mathrm{IL}$}

In addition to possessing high thermal stability (Section 2.1.2), the $\left[\mathrm{N}_{2220}\right]\left[\mathrm{HSO}_{4}\right]$ IL has been reported to serve other functions. The IL acts as an effective Brønsted acid catalyst and a delignifying agent in biomass deconstruction [1,4,5,10,11], and a protein stabiliser [13].

In biomass deconstruction, the $\left[\mathrm{HSO}_{4}\right]^{-}$anion of the $\mathrm{IL}$ is responsible for catalysing the hydrolysis of major bonds, such as ester bonds, that link cellulose, hemicellulose and lignin polymers in biomass. The $\left[\mathrm{N}_{2220}\right]\left[\mathrm{HSO}_{4}\right]$ IL dissolves lignin while cellulose is insoluble in the IL, enabling the separation of lignin from cellulose to be easily done through a simple filtration process $[1,5,14,15]$. Various types of biomass have been tested, including 
switchgrass [4], Miscanthus [16], willow [10], oil palm and coconut husk [1]. A regional study showed that deconstruction of oil palm empty fruit bunches (OPEFB) and coconut husk in the $\left[\mathrm{N}_{2220}\right]\left[\mathrm{HSO}_{4}\right]: \mathrm{H}_{2} \mathrm{O}(80: 20 \mathrm{wt}: \mathrm{wt})$ at $120{ }^{\circ} \mathrm{C}$ for $2 \mathrm{~h}$ successfully recovered $30 \%$ cellulose-rich-material (CRM) from both biomass feedstocks [1].

The application of the $\left[\mathrm{N}_{2220}\right]\left[\mathrm{HSO}_{4}\right]$ IL is not exclusive to the biomass deconstruction. The IL can also be employed in the industry of chemical synthesis. Attri et al. utilised the $\left[\mathrm{N}_{2220}\right]\left[\mathrm{HSO}_{4}\right]$ IL to break carbon-carbon bonds in the cracking process of 2,2-dimethoxypropane [17], a common precursor used in the production of surfactants, polymer formulations and organic syntheses. Relative to the conventional method utilising a mixture of trichlorobenzene and $p$-toluene sulfonic acid, the use of the $\left[\mathrm{N}_{2220}\right]\left[\mathrm{HSO}_{4}\right]$ IL enhanced both conversion and selectivity by $50 \%$ and $20 \%$, respectively. More importantly, such enhancement was obtained at a temperature of $60{ }^{\circ} \mathrm{C}$ lower than that of the conventional method. The advantages of the $\left[\mathrm{N}_{2220}\right]\left[\mathrm{HSO}_{4}\right]$ IL have also been exploited in the Fischer esterification process [18]. The presence of the $\left[\mathrm{HSO}_{4}\right]^{-}$anion increases the ester yield, which then resides in the lighter phase away from the heavy IL phase. Thus, this clear separation eases the downstream process. Its recyclability while maintaining the quality and yield as well as its environmentally friendly trait, strengthens its potential in the chemical synthesis industry $[17,18]$

A study has shown the role of the $\left[\mathrm{N}_{2220}\right]\left[\mathrm{HSO}_{4}\right] \mathrm{IL}$ as a protein stabiliser, which is of interest to the biotechnological and pharmaceutical industries [13]. By using cyclic dipeptides as the protein model compounds, the $\left[\mathrm{N}_{2220}\right]\left[\mathrm{HSO}_{4}\right]$ IL is able to stabilize the native state of proteins and their functional groups due to the unfavourable interaction between the IL and the protein surface. This finding could catalyse the development of drug delivery applications in both industries.

\section{Conclusion}

It is hoped that the review has able to provide invaluable insight for scientists seeking to employ an economical IL in their research work. The $\left[\mathrm{N}_{2220}\right]\left[\mathrm{HSO}_{4}\right]$ IL could be an ideal selection for industrial solvent due to the following reasons: inexpensive (cost price is at $\$ 1.24 \mathrm{~kg}^{-1}$ ), thermally stable at high temperatures, synthesis pathway that is simple and ecofriendly consuming inexpensive reagents, and possess various functions with promising industrial application. It is also hoped that this review can attract enough interest to further expand the application of the $\left[\mathrm{N}_{2220}\right]\left[\mathrm{HSO}_{4}\right]$ IL to other research areas.

\section{References}

1. S. M. S. N. S. Zahari, A. T. M. Amin, N. M. Halim, F. A. Rosli, W. I. T. A. Halim, N. A. Samsukamal, B. Sasithran, N. A. Z. Ariffin, H. H. Azman, N. H. Hassan, Z. S. Othman, AIP Conference Proceedings 1972030024 (2018)

2. T. Welton, Proceedings of the Royal Society A: Mathematical, Physical and Engineering Science 471 (2015)

3. P. Hunt, Ionic Liquids

4. A. George, A. Brandt, K. Tran, S. M. S. N. S. Zahari, D. Klein-Marcuschamer, N. Sun, N. Sathitsuksanoh, J. Shi, V. Stavila, R. Parthasarathi, S. Singh, B.M. Holmes, T. Welton, B. A. Simmons, J. P. Hallett, Green Chemistry 171728 (2015)

5. S. M. S. N. Shikh Zahari, PhD of Imperial College London and Diploma of the Imperial College (DIC), Imperial College London, (2016)

6. O. Kuzmina, E. Symianakis, D. Godfrey, T. Albrecht, T. Welton, Physical Chemistry Chemical Physics 1921556 (2017) 
7. A. P. de los Ríos, F. J. Hernández-Fernández, L. J. Lozano, S. Sánchez, J. I. Moreno, C. Godínez, Journal of Chemical \& Engineering Data 55605 (2010)

8. Z. Karimi-Jaberi, B. Masoudi, A. Rahmani, K. Alborzi, Polycyclic Aromatic Compounds 1 (2017)

9. L. Chen, M. Sharifzadeh, N. Mac Dowell, T. Welton, N. Shah, J. P. Hallett, Green Chemistry 163098 (2014)

10. L. Weigand, S. Mostame, A. Brandt-Talbot, T. Welton, J. P. Hallett, Faraday Discussions 202331 (2017)

11. P. Verdia, A. Brandt, J. P. Hallett, M. J. Ray, T. Welton, Green Chemistry 161617 (2014)

12. M.S.Y. Jennings, BSc Final Year Project Report, Imperial College London (2014)

13. P. Attri, P. Venkatesu, Physical Chemistry Chemical Physics 136566 (2011)

14. A. Brandt, J. Grasvik, J. P. Hallett, T. Welton, Green Chemistry 15550 (2013)

15. A. Brandt, M. J. Ray, T. Q. To, D. J. Leak, R. J. Murphy, T. Welton, Green Chemistry 132489 (2011)

16. A. Brandt-Talbot, F. J. V. Gschwend, P. S. Fennell, T. M. Lammens, B. Tan, J. Weale, J. P. Hallett, Green Chemistry 193078 (2017)

17. C. Wang, L. Guo, H. Li, Y. Wang, J. Weng, L. Wu, Green Chemistry 8603 (2006)

18. P. A. Ganeshpure, G. George, J. Das, Journal of Molecular Catalysis A: Chemical 279 $182(2008)$ 